\title{
The Part-Time Doctoral Student Experience
}

\author{
Susan K. Gardner \\ University of Maine, Orono, \\ Maine, USA
}

Susan.k.gardner@maine.edu

\author{
Bryan Gopaul \\ University of Toronto, Ontario, \\ Canada
}

\begin{abstract}
Although scholarly interest in doctoral education has increased dramatically over the last two decades, much of this attention has focused on the experiences of doctoral students who are enrolled full-time in their programs. This study explored the experiences of 10 part-time doctoral students in different disciplines. Through semi-structured interviews with these students, we found that many of the issues surrounding these part-time doctoral students involved concerns related to balance, support, and fitting the mold of a "traditional" doctoral student. Importantly, while some of these issues are consistent with the experiences of full-time doctoral students, the experiences of part-time doctoral students are more complicated and required sustained and flexible efforts to adequately address. We conclude by suggesting both institutional and empirical efforts to better understand the complicated experiences of part-time doctoral students as well as to develop multi-faceted initiatives to support the experiences of this growing doctoral student population.
\end{abstract}

Keywords: part-time, socialization, non-traditional, doctoral students

\section{Introduction}

Investigations of the doctoral student experience have continued to populate the higher education literature throughout the United States (U.S.) and across the world. In particular, scholars have sought to understand how the doctoral student experience may contribute to or detract from what has been deemed an alarming rate of doctoral student completion, reported at a mere $57 \%$ (Council of Graduate Schools, 2008). However, the majority of this literature on the doctoral student experience has tended to focus on full-time students, thereby neglecting the growing body of part-time doctoral students on U.S. campuses.

The paucity of literature discussing part-time doctoral students in the U.S. might be attributed to several issues particular to this population. First, defining what it means to pursue a doctorate part-time can be challenging. For example, part-time status in the U.S. may be temporary or permanent, meaning that the student may transition between full-time and part-time status through-

Material published as part of this publication, either on-line or in print, is copyrighted by the Informing Science Institute. Permission to make digital or paper copy of part or all of these works for personal or classroom use is granted without fee provided that the copies are not made or distributed for profit or commercial advantage AND that copies 1) bear this notice in full and 2) give the full citation on the first page. It is permissible to abstract these works so long as credit is given. To copy in all other cases or to republish or to post on a server or to redistribute to lists requires specific permission and payment of a fee. Contact Publisher@InformingScience.org to request redistribution permission. out the doctoral program. At one point in the program, the doctoral student may pursue coursework full-time and then transition to part-time, whereas another student may be full-time during the academic year but part-time in the summer, or another who might be enrolled fulltime until the beginning of dissertation research. Second, institutions may define enrollment status differently (i.e., anyone registering for fewer than nine 
credits per semester would be considered part-time at one institution, whereas a different number of credits may differentiate such a student elsewhere). Third, because of this elusive status, the number of doctoral students who are identified as part-time in the U.S. at any given time is difficult to ascertain. While the majority of master's students are now reported to be part-time in the U.S. (Syverson, 1999), the majority of doctoral students across disciplines still are largely identified in a full-time status. In some literature, rough estimates of these part-time doctoral students have ranged from 6\% (Golde \& Dore, 2001) to 10\% (Syverson, 1999) and even as high as 12\% (Nettles \& Millett, 2006). The Council of Graduate Schools (2009) explained, "Even if current data sources are unable to provide a full picture of the participation of non-traditional students in graduate education, it is clear that the population is growing in sheer numbers and that this growth will likely persist for at least the next decade" (p. 1).

Given this growing body of the doctoral student population in the U.S., more research is warranted that better assists faculty, administrators, and policy-makers in understanding the distinct needs and experiences of part-time doctoral students. In this study, we sought to provide a baseline understanding by asking, "What are the experiences of part-time doctoral students at one institution in the U.S.?" We begin with a discussion of the literature that exists about the part-time doctoral student experience in the U.S., followed by the methods used in the study. We then provide a discussion of the findings as well as implications for policy, practice, and future research.

\section{Part-Time Doctoral Students: A Literature Review}

Understanding the part-time doctoral student experience is by no means simple. Indeed, the complexity of merely defining what it means to be a part-time doctoral student may explain the lack of literature about this population. Many scholars have pointed out the difficulty of accounting for enrollment status in understanding doctoral student outcomes such as attrition and completion (Bowen \& Rudenstine, 1992; Council of Graduate Schools, 2004), and the lack of national data in this regard further exacerbates the problem in the U.S. (Bowen \& Rudenstine 1992). To illustrate, The Survey of Earned Doctorates, which collects data on all graduating doctoral students in the U.S. each year, does not even ask students about part-time enrollment status (Hall, Evans, \& Nerad, 2006). At the same time, there is a normative expectation that doctoral study is a full-time pursuit in the U.S. The Council of Graduate Schools (2005) comments on this expectation saying that full-time study "allows students to concentrate exclusively on course work or research; to acquire the habits, attitudes, skills, and insights necessary for attaining the Ph.D.; and to find opportunities to work closely with the professors and other students" (p. 21). In fact, many studies have found that full-time pursuit of the doctoral program results in higher persistence and completion rates (Clewell, 1987; Girves \& Wemmerus, 1988; Nettles \& Millett, 2006). Nevertheless, up to $12 \%$ of doctoral students may choose to pursue their degree part-time for at least a portion of their program in the U.S. (Nettles \& Millett, 2006), whereas other countries have estimated part-time enrollment at even higher rates. Part-time doctoral student enrollment in Australia has been documented from 38\% (Neumann \& Rodwell, 2009) to 47\% (Hall et al., 2006), and up to $63 \%$ in the United Kingdom (Deem \& Brehony, 2000).

The proportion of part-time doctoral students tends to vary by discipline. At the doctoral level, it is the discipline that most often dictates the student's experience (Golde, 2005) as the discipline encompasses particular cultural and methodological underpinnings that set it apart from other fields of study (Biglan, 1973a). In turn, the representation of part-time students in a given discipline can also be thought of as reflecting its culture. For example, a significantly higher number of students in professional fields such as education and social work will enroll part-time as compared to those students in the sciences, where part-time enrollment may be all but non-existent (Biegel, Hokenstad, Singer, \& Guo, 2006; Nettles \& Millett, 2006; Smith, 2000). In other fields, such as engineering, this part-time status is becoming increasingly common as universities strive 
to accommodate working professionals (Davis \& McCuen, 1995). In fact, it is the focus on the full-time professional that has brought more attention to the part-time doctoral student experience (Syverson, 1999). As access to and demand for distance education technologies increase, for instance, one might expect even more attention to be focused on these part-time doctoral students.

From the research that has been conducted on these students, part-time doctoral students have been found to have dissimilar experiences from their full-time counterparts. Specifically, parttime students have been found to be less satisfied with their doctoral experiences (Nettles \& Millett, 2006; Neumann \& Rodwell, 2009), to be less scholarly engaged than their full-time peers (Biegel et al., 2006; Davis \& McCuen, 1995; Nora \& Snyder, 2007), and are often perceived as less committed than their full-time counterparts (Curran, 1987). The reasons for these disparities between part-time and full-time doctoral students are multifaceted. Primarily, given their often challenging schedules that require full-time employment, part-time doctoral students often find themselves struggling to balance their roles as student and professional (Curran, 1987; Davis \& McCuen, 1995; Smith, 2000; Watts, 2008). As such, Smith (2000) remarked, "The crucial aspect of 'part-timeness' has very little to do with credits taken. Rather, the issue is one of time pressures because of full-time employment" (p. 362). In addition, the financial pressures that parttime students face may account for some of these disparities, particularly given their likelihood to be older, to have dependents, and be married (Choy \& Cataldi, 2006). Since the majority of financial support to graduate students is often ear-marked for full-time students (Nora \& Snyder, 2007; Syverson, 1999), part-time students must often find their own resources to subsidize their graduate work.

Taken together, while part-time doctoral students constitute a growing population of graduate students in the U.S., relatively little empirical research has been conducted to examine their experiences. In the studies conducted, most utilized part-time status as one variable to consider among many (Girves \& Wemmerus, 1988; Nettles \& Millett, 2006), rather than focusing solely on this population's experience. Moreover, those studies focusing primarily on part-time students were conducted within one discipline at one institution (e.g., Smith, 2000). The remainder of literature on part-time doctoral students often tends to be anecdotal in nature, thereby limiting the scope of understanding of this population's experience in graduate education.

\section{Doctoral Student Socialization: A Framework}

The majority of the literature on the doctoral student experience in the U.S. has focused on the conceptual underpinnings of socialization (Mendoza \& Gardner, 2010). Broadly defined, socialization is the process through which an individual learns to adopt the values, skills, attitudes, norms, and knowledge needed for membership in a given society, group, or organization (Bragg, 1976; Golde, 1998; Tierney, 1997). Bragg discussed socialization in higher education settings as encompassing three major elements: (a) the interaction of students with the structures of the educational setting, (b) the interaction between students and faculty members, and (c) the interaction among students in the same educational program.

In regard to graduate students, the socialization process is delineated even further as consisting of a dual socialization: to the degree program as well as to the future profession (Golde 1998). A widely used framework of socialization for understanding the graduate student experience is that of Weidman, Twale, and Stein (2001), who based their work on that of Thornton and Nardi (1975). As illustrated in Figure 1, the Weidman et al. framework of graduate student socialization includes the core experience of the degree program, as framed by the institutional culture of the university; the socialization processes of interaction, integration, and learning; and the core elements of socialization, including knowledge acquisition, investment, and involvement. Specifically, students are socialized through interaction with faculty and peers and integrated into the department's activities and the culture of their disciplines. At the same time, students are also in- 
fluenced by their own backgrounds and predispositions, their professional communities, as well as their personal communities. As the socialization process unfolds, students then transition to novice professional practitioners, wherein commitment to and identification with the chosen professional career occurs.

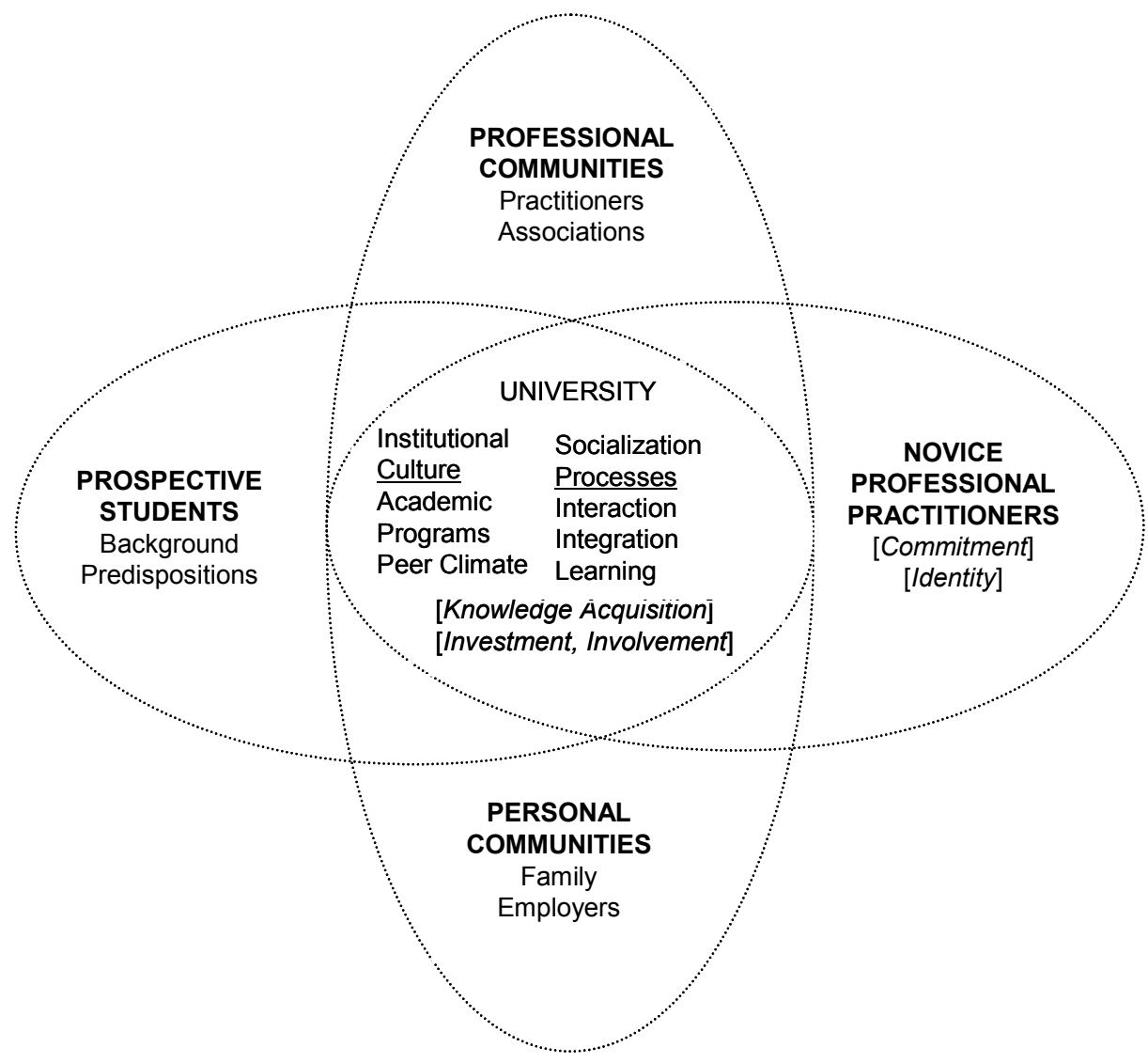

Figure 1: Based on Weidman, Twale, and Stein's (2001) Graduate Socialization Framework

Several key terms in Weidman et al.'s (2001) framework merit definition. The idea of knowledge acquisition refers to the student's ability "to understand and acclimate to the academic culture, to meet faculty standards, and to perform role expectations" (p. 55). The concept of investment is defined as "the degree of time and energy that graduate students put forth in meeting program requirements" (p. 63). Involvement, on the other hand, encompasses the student's attachment to the program, the profession, and the discipline.

In regard to part-time doctoral students and their socialization process, therefore, the amount of time dedicated by the student to the doctoral experience may result in what Weidman et al. (2001) expressed as a diminished sense of investment and involvement. One area in which part-time students will experience the lessened amount of investment and involvement is with their peers. Speaking specifically to the part-time student experience, they commented on the benefit of cohort programs that allow for additional peer support: "Cohorts offer much needed consolation to the part-time student, who rarely experiences the university beyond scheduled classes" (p. 82).

While socialization has become a common lens through which the doctoral student experience is understood, it is often assumed that the student will be enrolled full-time to reap the benefits of a full socialization experience. Given the sparse nature of literature on part-time doctoral students, the concept of socialization is one that deserves fuller attention in understanding their experience and how these experiences may translate to their socialization outcomes. 


\section{Methods}

The research question guiding this study was, "What are the experiences of part-time doctoral students at one research institution in the U.S.?" The focus on one institutional context was purposeful for several reasons. First, due to the varying definition of part-time enrollment status in the U.S. as one that is often based on institutional definitions of credit hours (Hall et al., 2006), limiting the scope of this study to one institution was appropriate. Second, institutional context will often provide parameters around the doctoral experience in regard to policies and procedures as well as the larger institutional culture that influences the individual disciplines and department (Gardner, 2010), and thereby the socialization of the students (Weidman et al., 2001). Finally, given the relatively sparse nature of empirical data on part-time doctoral students, an exploratory case study in one institutional setting was warranted (Maxwell, 1996). In this way, qualitative methods were best suited for this study as they allow for:

(a) An understanding of the meaning, for participants in the study, of the events, situations, and actions they are involved with and of the accounts that they give of their lives and experiences.

(b) An understanding of the particular context within which the participants act, and the influence that this context has on their actions.

(c) The identification of unanticipated phenomena and influences (Maxwell. 1996, pp. 18-19).

Specifically, the setting under examination in this qualitative study was a mid-sized research university located in the U.S. At the time of the study in the spring and summer of 2010, the doctoral programs at the institution numbered close to 40 , with the majority of doctoral students in the field of education. Graduate students comprise $21 \%$ of all enrollment at the university, with roughly half of those students enrolling part-time.

\begin{tabular}{|c|l|l|}
\hline \multicolumn{3}{|c|}{ Table 1: Degree-Granting Programs by Biglan's Classification } \\
\hline TASK AREA & \multicolumn{1}{|c|}{ HARD } & \multicolumn{1}{c|}{ SOFT } \\
\hline Pure & $\begin{array}{l}\text { Animal Science, Biochemistry, Bio- } \\
\text { medical Science, Biological Science, } \\
\text { Chemistry, Earth Sciences, Ecology } \\
\text { and Environmental Sciences, Marine } \\
\text { Biology, Microbiology, Oceanogra- } \\
\text { phy, Physics, Zoology }\end{array}$ & $\begin{array}{l}\text { English, History, Psychology, Clini- } \\
\text { cal Psychology, Communication }\end{array}$ \\
\hline Applied & $\begin{array}{l}\text { Chemical Engineering, Civil Engi- } \\
\text { neering, Computer Science, Electrical } \\
\text { Engineering, Food and Nutrition Sci- } \\
\text { ences, Forest Resources, Forestry, } \\
\text { Mechanical Engineering, Spatial In- } \\
\text { formation Science, Wildlife Ecology }\end{array}$ & $\begin{array}{l}\text { Counselor Education, Educational } \\
\text { Leadership, Higher Education, Liter- } \\
\text { acy Education }\end{array}$ \\
\hline
\end{tabular}

Participants for the study included 10 doctoral students who self-identified as part-time in diverse disciplines. We discerned and then categorized disciplinary differences using Biglan's (1973b) classification, a commonly used conceptualization of disciplines that categorizes disciplines by their emphasis on paradigmatic consensus (hard versus soft) as well as its research mode (pure versus applied, see Table 1). From this classification, we sent emails to the graduate program coordinators and department chairs of these representative programs to solicit student participation. From these email solicitations, we chose a total of 10 doctoral students to represent the diversity 
of disciplines at the institution. These students also represented diversity in regard to gender as well as their status in the program (see Table 2).

\begin{tabular}{|l|l|l|l|l|}
\hline \multicolumn{5}{|c|}{ Table 2: Participants by Biglan Classification, Gender, Age, and Program Status } \\
\hline PSEUDONYM & \multicolumn{1}{|c|}{ BIGLAN } & GENDER & \multicolumn{1}{c|}{ AGE } & $\begin{array}{c}\text { PROGRAM } \\
\text { STATUS }\end{array}$ \\
\hline Nancy & Hard-Pure & Female & 52 & Coursework \\
\hline James & Soft-Applied & Male & 41 & Dissertation \\
\hline Michael & Soft-Pure & Male & 53 & Coursework \\
\hline Peter & Soft-Pure & Male & 46 & Dissertation \\
\hline Jeffrey & Hard-Applied & Male & 51 & Dissertation \\
\hline Robert & Hard-Applied & Male & 33 & Dissertation \\
\hline Mark & Hard-Applied & Male & 38 & Dissertation \\
\hline Lisa & Soft-Applied & Female & 42 & Coursework \\
\hline Thomas & Soft-Applied & Male & 31 & Coursework \\
\hline Janet & Soft-Applied & Female & 52 & Coursework \\
\hline
\end{tabular}

After receiving informed consent, we conducted interviews with the 10 doctoral students included in the study in the spring and summer of 2010 through face-to-face interviews utilizing a looselystructured protocol based on the framework of socialization by Bragg (1976) and Weidman et al. (2001) (see Appendix). This protocol allowed participants to diverge from the main topics and to further explore concepts and ideas. Interviews lasted for approximately 45 to 90 minutes and were audio-taped and later transcribed verbatim.

Analysis of the data was conducted through the use of the constant comparative method, "a research design for multi-data sources, which is like analytic induction in that the formal analysis begins early in the study and is nearly completed by the end of data collection" (Bogdan \& Biklen, 2003, p. 66). The study utilized Glaser's (1978) steps in data analysis, wherein we began collecting the data and then sought out key issues, events, or activities in the data that became main categories for focus. We then continued collecting data to provide undergirding for these main categories. We then wrote about the categories explored, keeping in mind past incidents while searching for new, while working with the data and emerging model to discover relationships. Finally, we sampled, coded, and wrote with the core categories in mind. Glaser's steps for analysis also allowed for emergent themes to develop from the data and provided a means by which large amounts of data were compressed into meaningful units for analysis. We then utilized concepts of graduate student socialization (Bragg, 1976; Weidman et al., 2001) to better understand the dimensions along which students responses varied.

We verified trustworthiness of the analysis through peer debriefing, wherein we separately analyzed the data and then compared analysis to develop the resulting themes. Member checking was also utilized, as participants were sent an email encapsulating the themes that emerged from their 
interviews and asked to verify these themes. All students verified that these themes represented their recollection of the interviews.

\section{Findings}

From the analysis of the data resulting from the interviews with the 10 part-time doctoral students, three themes emerged. These themes, each discussed in turn below, include the three interrelated concepts of (a) balance, (b) support, and (c) fitting the mold.

\section{Balance}

Reflecting the existing literature on this student population (e.g., Choy \& Cataldi, 2006; Watts, 2008), all 10 of the students in the study held full-time positions while pursuing their doctoral degrees. Also reflecting the work of Choy and Cataldi and of Watts, most also had family responsibilities in addition to their graduate education. And, while balance is a common concern among all doctoral students (Gardner, 2007), the balance these students feel they have to strike is profoundly different and significantly more intense than their full-time peers. For example, several of the students discussed having to wear different hats, particularly when their professional focus and graduate program focus did not align, like Janet, who remarked, "And that constant kind of pressure on your mind that, okay, I gotta get this done, gotta get that done. Where am I gonna fit it in, when am I gonna fit it in?" In particular, Janet explained the dilemma that many of the other students described in regard to their work-academic balance:

I'm certainly still expected to carry my weight with all the different projects and things. Sometimes there's a lack of awareness of just how much I have to do outside of school. You know, I have this pressure that I'm not going to let what I'm doing in my grad program cause my work to suffer. So, sometimes that means foregoing something that I might really want to do, because I need to finish something at school before I can go home and, you know, finish up a paper.

In this vein, many of the students commented on the sacrifices and compromises they have to make in one aspect of their life or another to be able to balance all of the roles in their lives. Thomas explained, "I guess part of what it means to me to be a part-time doctoral student is needing to continually balance the tugs in different directions. It also means not being able to accomplish everything I want. There are always compromises that I've felt I needed to make." Lisa similarly remarked, "I just I think you let a lot more slip part-time, because the time's not there; the energy's not there to address things." For many students, the sacrifices came into their relationships with their friends, family, and children. Mark, a single parent, talked about how the push and pull of his many demands affects his daughter, "I think there's a component of, 'Well, none of my friends' parents are working as hard as you're working."

As such, the balancing act required to manage their many roles became a source for stress for the students. Michael remarked, "It bugs me. I cannot spend as much time as a full-time student, doing as much as I would like to." As such, the subject of guilt came up a lot for many of the students: "I just feel guilty all the time," Janet explained. James echoed these sentiments, saying:

I find that the hardest part is trying to get myself to the place where my - where my concentration, where my mindset is sufficiently focused to accomplish something decent. It's not the actual work that's so hard, it's getting yourself mentally into the space where you can work. And having enough time that's uninterrupted that you can do that. And not being able to push aside all the other things. You know, oh, you have a kid who's not doing well at school. Or you've got, you know, whatever. 
As a result, many of the students discussed a level of satisficing in their work, or doing the minimal amount of work they could make it passable or satisfactory. Mark, now working on his dissertation, sighed as he said, "I guess this part-time dissertation experience...I'm glad that I've been given the opportunity, but I'm not going to look back on this and say this is the point where I academically shined." As such, Mark wondered aloud, "There are times when I think that because of my part-time status, also because of my full-time job and the teaching and everything like that, I kinda got the feeling that sometimes they may be cutting me a little bit of slack." This notion of being cut some slack was also communicated by other students. Nancy remarked, "Being a part-time student means that the professors are fairly cognizant of the fact that you don't

have large number of hours to devote to the coursework. So I think there's some effort to create assignments and work projects that are reasonably doable." Importantly, the participants framed this "cutting of slack" as indicative of flexibility by faculty members to recognize the complicated dynamics of part-time doctoral student status.

\section{Support}

To manage the stress of the balancing act that they all described, these part-time students also discussed their sources of support. While most full-time doctoral students will find extensive support from their graduate advisors (Bargar \& Mayo-Chamberlain, 1983; Barnes \& Austin, 2009) and from their student peers (Gardner, 2007; Sweitzer, 2009), the part-time students in this study rarely discussed the support from these entities. Instead, it was most often their partners, children, and places of employment that provided them the most support in this endeavor. For these students, family members were the most often discussed source of support in their lives. Like Mark, who shared, "My 10 year-old daughter has been through everything with me. She is probably more supportive than any 10 year-old needs to be." For others, it was their partners and spouses that provided the most support; "It' $d$ be tough to rate the most [supportive person]. I guess if I had to pick one, I'd probably pick [my fiancée] because she's suffering the most, if you will, from the hours I spend on this. Her patience with that is extremely important," Thomas explained. Janet also mentioned how important her husband's role was in providing her support, particularly in regard to chores, "My husband bears more of the brunt. My husband has to pick up more things around the house, like, literally and figuratively. You know, he does more dishes. He cooks more meals. He does more loads of laundry."

The second most-discussed source of support for these part-time students came from their employers and co-workers. "Well, my staff is fantastic. If I did not have those people behind me and knowing their jobs, I could not do this. And that makes me feel very good," said Michael. James offered this advice to other part-time students based on his own experience:

If you're not in a job that is supportive, you need to be in a job that is supportive, because if you're not, I don't see how you could possibly finish. There's just no way. So, before you start your program, make sure you have a job that's gonna allow you the kind of flexibility that you're gonna have to have to do this.

Robert summarized the support he receives at work succinctly, "Work also is very supportive. If I didn't have the flexibility that they've afforded me, there is no way I could complete my degree."

When students did discuss the support from their faculty, it was often tied to the responsiveness of their faculty, the timeliness of their feedback, and their level of flexibility given the many demands in the students' lives. Mark shared, "I've had good response time. Very good response time actually. Every time I've submitted anything to [my advisor], he comes back quickly." Similarly, Peter remarked:

The department's been pretty good, too. Letting me kind of do this on my own terms, I suppose. Because I didn't know if that's the way of things for part-time students or not; I 
didn't even really care. I just kind of said, "Well, this is how I'm going to do it, if you want to, okay. If not, I'm okay with that, too."

The students involved in cohort programs, however, spoke differently of their peer relationships. Lisa explained, "I think there's a big difference between part-time and being with a cohort. Had I been part-time and not with a cohort, I don't know that I would have developed these same relationships." Robert, who was involved with a National Science Foundation Integrative Graduate Education Research and Traineeship (IGERT) during his coursework, found his cohort experience to be his main source of support during that time: "It worked out well that my cohort members, a lot of times their availability was more at night or during lunch as well, so everything fit together really nicely."

Those without this cohort experience, however, felt they could benefit from such a thing, particularly as many of the students talked about the lack of peer interaction they had. James remarked, "It would be so nice to think about going through as a cohort. I mean, wow, wouldn't that be fun? You've got common things. You're on this path together. That would be great, but..." Indeed, when asked about his peer relationships, he said, "Peer relationships? I don't have any." Feelings of isolation were a common point among many of the students in this way. Even, Michael, who talked positively about his peer relationships, mentioned, "I'd say that, that my experience has been positive, but very, very minimal."

\section{Fitting the Mold}

As such, the majority of the students lamented the fact that they did not have closer relationships with their faculty and peers, which they realized is a "normal" component of most students' doctoral programs. This normative idea of what it meant to be a doctoral student was one that most of them equated with being full-time and, for some, was a source of internal conflict and struggle. For example, Robert mentioned that he was never open about his part-time status in his program. He explained, "Many of my peers didn't know that I was working outside of school. It's not that I kept it hidden. I just never brought it up. I kind of wanted to fit the mold of a traditional student."

For others, their lack of fitting in surrounded their age in addition to their part-time status. As many part-time graduate students also tend to be older (Choy \& Cataldi, 2006; Syverson, 1999) than their full-time peers, this awareness of difference may not be surprising. Peter pointed out his many differences to his peers, "Me being a full-time teacher and kind of doing it a spare time sort of thing, not being on campus, and my age, too. I'm really non-traditional, I guess, for a $\mathrm{Ph}$.D. I'm in my mid-forties, so it's not like a career building block or something that I'm looking at it as."

This lack of fitting in, however, went beyond the students' peer interactions. Given the fact that the majority of graduate student financial support is often predicated on a full-time enrollment status (Choy \& Cataldi, 2006; Syverson, 1999), very little financial support is available to these students. Nancy explained, "I don't fit into anything that they could really justify giving me money for. I mean, I can't do work-study. I can't TA or anything like that. I suppose if they really got creative I could maybe do some research for them that's amenable to my situation."

Taken together, the lack of fitting in resulted in some of students feeling they were missing out on something. Like Michael, who feels he has had a generally positive experience as a part-time student, but wondered, "So it [has been] a positive experience, but yet I walk away feeling as though I have missed something and that I couldn't be a part of the overall process." Other participants noted that full-time status enabled a greater learning experience that encompassed more opportunities for reflection and sustained engagement with theories, research, and readings as well as focused interactions with peers and faculty members. Specifically, Lisa noted, "It's very scattered to have a full-time job with lots of responsibilities and then to try and do courses that are 
more than just the requirements and actually getting the learning, thinking, and processing that should occur." Also, in speaking about how his experiences would be different as a full-time student, Thomas commented, "But, certainly, being able to focus on the course work and feel like I was reading things as thoroughly as I wanted to and producing project as thoroughly as I wanted to would be different." The opportunity to digest, reflect on and debate the research and topics learned during their courses was extremely significant to the experiences of doctoral students and an important layer that differentiated the experiences of these part-time doctoral students.

An important dynamic that complemented these issues related to the learning experience involved the perception that part-time students were missing out on important, daily interactions with peers and faculty members. As Robert highlighted, "Where I do have issues is I know that a lot of my friends are doing full-time [studies]. They have a lot of opportunities during the day to work on research...they are immersed in it throughout the day, interacting with other students in the $\mathrm{PhD}$ program and peers within our program. I miss a lot of that interaction [when] I'm working during the day." Further, Peter echoed similar themes as he stated, "Full-time would definitely keep me on task, bring me more connections, face-to-face time, more opportunity for on-campus research."

Translating back to the theme of support, students like Jeffrey explained that they had to forge new paths in their programs. He stated, "I have to figure this out as I go. There is no map on how to do this." Having to forge these new paths resulted in a lack of isolation in some of the students' experiences. James shared, "What's interesting is how few people really understand how hard it is. So, your family, like my parents will be happy, and my mom will be proud, you know, the first kid to do whatever. But there [are] very few people that really understand how much commitment this takes to actually bring to fruition." Even with support, Mark discussed, it is difficult:

I have noted that there are times where, regardless of the support you are getting, where there are emotional strains. And, you know, I don't have resource or infrastructure recommendations for supporting part-time PhDs. I think it's perhaps just a game to go through.

\section{Discussion}

The literature on the doctoral education experience tends to chronicle the life of doctoral students as one that requires balance and support (Gardner, 2007; Gardner, 2008b, 2009; Grant-Vallone \& Ensher, 2000; Lovitts, 2001). For the part-time doctoral students in this study, these issues were no less prominent but, at the same time, the kinds of balance and support these students discussed were very different from the reports of full-time doctoral students in other research. In this way, the current study adds to the existing literature by providing one of few empirical investigations into the part-time doctoral student experience and its dynamically different nature from that of full-time students. Similarly, while Gardner (2008a) briefly touched upon the experience of parttime doctoral students and their experience of not "fitting the mold" of graduate school, the students in this study were explicit in their awareness of their "otherness" in relation to their peers. This otherness or marginality can have a significant influence upon students' feelings of belonging and success (Schlossberg, 1984). In this way, the socialization of these part-time students is one that, in many ways, they consider "lesser than" that of their peers. Many questioned what they were "missing out on" by not being fully in the world of their full-time peers. This notion of "missing out on" encompassed both individual aspects of learning as well as broader issues related to research intensity, peer networking, and overall engagement with campus life.

Certainly, discipline does make a difference in this regard. For example, in education, where often part-time status is the norm (Nettles \& Millett, 2006), the students in this study discussed a 
much less challenging experience as opposed to the students in the sciences and engineering, who were more likely to be alone in their experience. Mark explained his difficulty in this experience, sharing, "I wouldn't recommend this for anyone. There will obviously be people who are put in this position and will do it. I presume anyone who would do it part-time, they're doing it because they are working."

These isolated students were also aware that few understand the burden they carry in trying to balance their many roles successfully. The students who were part-time in cohort programs (or those programs with a normative expectation that students would be part-time) discussed a tremendously different experience from those students who were one of the few to pursue their degrees part-time. The cohort students talked about knowing that their peers and faculty understood the many demands of their lives and that the program was designed to fit these needs. In this way, the students involved in cohorts spoke to the same level of peer support as full-time students have discussed in previous research (Gardner, 2007, 2008b). Those students outside of the cohort experience, however, talked about finding many obstacles to making their part-time status more manageable, such as a lack of funding, a lack of availability of campus resources after normal business hours, and a general lack of understanding. James explained his frustration with the lack of support for part-time status:

I don't think we do a very good job of supporting people doing this kind of thing. I don't think our society does a very good job of supporting people. I mean beyond just what the university could do. You know, it's like we're speaking out of both sides of our mouth as a nation. We're saying, "Oh, it's so important to have people that have a higher degree of training. We need people that are doing these kinds of things." But yet there really aren't a lot of supports to make it happen, not nearly to the degree that would be necessary.

In regard to socialization, then, the majority of the students in this study discussed a lack of investment, involvement, and knowledge acquisition, as discussed by Weidman et al. (2001). More specifically, the majority of the students discussed how time and other professional and personal responsibilities took away from their investment, which then translated to a lack of involvement. For some, the lack of these two elements resulted in a feeling of a lack of knowledge acquisition or missing out on some other core components of learning in their programs. By contrast, the students who were involved in cohort programs, or those designed for their part-time status, did not mention a lack of these socialization elements. It could be that these students' experiences are designed purposefully by faculty, who know that these students will have ultimately less time to contribute to their doctoral programs. It may also be that the normative expectations for investment, involvement, and knowledge acquisition are based upon those they observe. Since cohort students will rarely engage with full-time students these students may, for all intents and purposes, not know what they are missing. Certainly, future research should examine faculty perceptions in regard to the socialization experiences of full- and part-time doctoral students to better ascertain such differences in outcomes.

Not all doctoral programs welcome part-time students and some faculty may even caution against pursuing a program part-time. But for those campuses that wish to grow their part-time doctoral student populations and to better support their current part-time students, we offer the following recommendations for policy and practice. First, campuses and programs should move beyond the level of benign neglect that many of the students in the study discussed experiencing. In particular, considering what services and supports that doctoral students utilize and making them available is an important first step. For example, the students in this study discussed how vital their access to library materials online and distance were to their experiences. Continuing to expand other services such as financial aid and graduate services to more online and distance formats will also be valuable to this student population. 
Similarly, on-campus resources such as writing centers, counseling centers, and childcare centers might consider holding evening and weekend hours for the part-time contingent. Second, the lack of peer support is a tremendous concern for students who may not be part of a cohort. Providing a campus-wide peer group that focuses on part-time graduate students might be helpful. However, campuses should be aware that adding other responsibilities and time commitments may ultimately feel like more of a burden than a help to these students. Instead, providing online support groups, blogs, and forums might be a better way to access support when they need it and have time to pursue it. Also, organizing research or professional-themed events or discussions may encourage part-time student participation. Importantly, considerable commitment to "planning ahead" is necessary for this part-time student population. Having to balance a host of issues, both personal and professional, often negates the participation of part-time doctoral students, so efforts to arrange and to confirm this programming with considerable notice to students would assist with part-time student participation. Third, scheduling courses and other requirements in a fashion that relates to a full-time working professional's needs is also important. Again, the use of distance technologies can be helpful in this regard. In general, offering more targeted support for these students may also, in the end, open more opportunities for this growing demographic in graduate education.

This exploratory study offered an empirical perspective into the lives of 10 part-time doctoral students but more research must be conducted on this burgeoning population. For example, examining part-time doctoral student experiences by disciplines, by cohort programs, and by institutional settings is needed, as is examining different demographic segments of this population including those with and without dependents, different age ranges, as well as different socioeconomic backgrounds. Moreover, examining the programmatic experiences at different turning points (i.e., coursework, examination, dissertation) would also be valuable. Finally, we offered only one national perspective in this study. Future studies should examine how different countries and their norms differ based on expectations for coursework and enrollment, for example. In short, while the part-time doctoral student contingent continues to grow so should our understanding.

\section{References}

Bargar, R. R., \& Mayo-Chamberlain, J. (1983). Advisor and advisee issues in doctoral education. The Journal of Higher Education, 54, 407-432.

Barnes, B. J., \& Austin, A. E. (2009). The role of doctoral advisors: A look at advising from the advisor's perspective. Innovative Higher Education, 33, 297-315.

Biegel, D. E., Hokenstad, M. C., Singer, M. I., \& Guo, S. (2006). One school's experience in reconceptualizing part-time doctoral education in social work. Journal of Social Work Education, 42, 231-247.

Biglan, A. (1973a). The characteristics of subject matter in different academic areas. Journal of Applied Psychology, 57, 195-203.

Biglan, A. (1973b). Relationships between subject matter characteristics and the structure and output of university departments. Journal of Applied Psychology, 57, 204-213.

Bogdan, R. C., \& Biklen, S. K. (2003). Qualitative research for education: An introduction to theories and methods. Boston: Allyn and Bacon.

Bowen, W. G., \& Rudenstine, N. L. (1992). In pursuit of the Ph.D. Princeton, NJ: Princeton University Press.

Bragg, A. K. (1976). The socialization process in higher education. Washington, DC: The George Washington University. 
Choy, S. P., \& Cataldi, E. F. (2006). Student financing of graduate and first-professional education, 200304. Washington, DC: National Center for Education Statistics (NCES 2006-185).

Clewell, B. C. (1987). Retention of Black and Hispanic doctoral students. Research Report ETS RR-87-10. Princeton, NJ: Educational Testing Services.

Council of Graduate Schools. (2004). Ph.D. completion and attrition: Policy, numbers, leadership, and next steps. Washington, DC: Author.

Council of Graduate Schools. (2005). The doctor of philosophy degree: A policy statement. Washington, DC: Author.

Council of Graduate Schools. (2008). Ph.D. completion and attrition: Analysis of baseline program data from the Ph.D. completion project. Washington, DC: Author.

Council of Graduate Schools. (2009). Data sources: Non-traditional students in graduate education. Washington, DC: Author.

Curran, C. C. (1987). Dealing with the distant learner as part-time learner. Journal of Education for Library and Information Science, 27, 240-246.

Davis, A. P., \& McCuen, R. H. (1995). Part-time graduate education: Obstacles, conflicts, and suggestions. Journal of Professional Issues in Engineering Education and Practice, 121(2), 108-113.

Deem, R., \& Brehony, K. J. (2000). Doctoral students' access to research cultures - Are some more unequal than others? Studies in Higher Education, 25, 149-165.

Gardner, S. K. (2007). "I heard it through the grapevine": Doctoral student socialization in chemistry and history. Higher Education, 54, 723-740.

Gardner, S. K. (2008a). Fitting the mold of graduate school. Innovative Higher Education, 33, 125-138.

Gardner, S. K. (2008b). "What's too much and what's too little?": The process of becoming an independent researcher in doctoral education. The Journal of Higher Education, 79, 326-350.

Gardner, S. K. (2009). Doctoral student development: Phases of challenge and support. San Francisco: Jossey-Bass.

Gardner, S. K. (2010). Keeping up with the Joneses: Socialization and culture in doctoral education at one striving institution. Journal of Higher Education, 81(658-679).

Girves, J. E., \& Wemmerus, V. (1988). Developing models of graduate student degree progress. Journal of Higher Education, 59(2), 163-189.

Glaser, B. (1978). Theoretical sensitivity: Advances in the methodology of grounded theory. Mill Valley, CA: Sociology Press.

Golde, C. M. (1998). Beginning graduate school: Explaining first-year doctoral attrition. In M. S. Anderson (Ed.), The experience of being in graduate school: An exploration (pp. 55-64). San Francisco, CA: Jossey-Bass.

Golde, C. M. (2005). The role of the department and discipline in doctoral student attrition: Lessons from four departments. Journal of Higher Education, 76, 669-700.

Golde, C. M., \& Dore, T. M. (2001). At cross purposes: What the experiences of doctoral students reveal about doctoral education. Retrieved January 24, 2008, from http://www.phd-survey.org

Grant-Vallone, E. J., \& Ensher, E. A. (2000). Effects of peer mentoring on types of mentor support, program satisfaction and graduate student stress: A dyadic perspective. Journal of College Student Development, 41(6), 637-642.

Hall, F. L., Evans, B., \& Nerad, M. (2006). Feasibility of international comparisons of PhD program times-to-degree and completion rates. Paper presented at the Quality in Postgraduate Research Conference, Adelaide, Australia. 
Lovitts, B. E. (2001). Leaving the ivory tower: The causes and consequences of departure from doctoral study. Lanham, MD: Rowman and Littlefield.

Maxwell, J. A. (1996). Qualitative research design: An interactive approach. Thousand Oaks, CA: Sage.

Mendoza, P., \& Gardner, S. K. (2010). The PhD in the United States. In S. K. Gardner \& P. Mendoza (Eds.), On becoming a scholar: Socialization and development in doctoral education (pp. 11-26). Sterling, VA: Stylus.

Nettles, M. T., \& Millett, C. M. (2006). Three magic letters: Getting to Ph.D. Baltimore: The Johns Hopkins University Press.

Neumann, R., \& Rodwell, J. (2009). The 'invisible' part-time research students: A case study of satisfaction and completion. Studies in Higher Education, 34, 55-68.

Nora, A., \& Snyder, B. P. (2007). Structural differences in scholarly engagement among full-and part-time doctoral students. Paper presented at the annual meeting of the American Educational Research Association, Chicago, IL, Chicago, IL.

Schlossberg, N., K. (1984). Counseling adults in transition: Linking practice with theory. New York: Springer.

Smith, P. R. (2000). A meeting of cultures: Part-time students in an Ed.D. program. International Journal of Leadership in Education, 3, 359-380.

Sweitzer, V. (2009). Towards a theory of doctoral student professional identity development: A developmental networks approach. The Journal of Higher Education, 80, 1-33.

Syverson, P. D. (1999). Part-time study plus full-time employment: The new way to go to graduate school. Education Statistics Quarterly, 1(3), 13-15.

Thornton, R., \& Nardi, P. M. (1975). The dynamics of role acquisition. American Journal of Sociology, 80, 870-885.

Tierney, W. G. (1997). Organizational socialization in higher education. The Journal of Higher Education, $68,1-16$.

Watts, J. H. (2008). Challenges of supervising part-time PhD students: Towards student-centered practice. Teaching in Higher Education, 13, 369-373.

Weidman, J. C., Twale, D. J., \& Stein, E. L. (2001). Socialization of graduate and professional students in higher education: A perilous passage? San Francisco: Jossey-Bass. 


\section{Appendix: Interview Protocol}

1. Where are you currently in your program (beginning, end of coursework, exams, dissertation)?

2. In what field are you receiving your doctorate?

3 . When did you begin your program?

4. When did you complete your undergraduate degree? (from where/what field?)

a. Were you enrolled part or full-time?

5. Did you get a master's degree first?

a. If so, in what area, and from where?

b. For that degree, did you enroll part-time or full-time?

6. Did you take any time off between your undergrad/master's and/or master's/doctoral degree?

a. If yes, how long?

b. Why?

7. What are you planning to do when you complete the degree?

8. Are you single or partnered?

9. Any dependents?

a. If so, how many and ages?

10. How many credits do you take on average each semester? Summer?

a. Has this changed over the course of your program? If so, why?

11. Do you work outside of school?

a. If so, how many hours?

b. Has this changed since beginning your program?

c. Is this work related to your graduate program?

12. How do you define what it means to be a "part-time" student?

13. Why did you decide to pursue your doctorate part-time?

14. Have you received any funding from the program or the university for your studies?

15. Tell me about your relationships with the faculty in your program.

16. Have you had the opportunity to conduct research with faculty in your program?

a. If so, how was this experience?

b. If not, would you like to do so? Why or why not?

17. What about your relationships with other doctoral students?

a. Are these relationships different with other part-time versus full-time students?

18. If you are working, how supportive is your workplace/boss of your studies?

19. What do your family and friends think of your studies?

20. Talk to me about the challenges you face in your doctoral program.

a. Do you think these would be different if you were enrolled full-time?

21. From whom or from where do you receive the most support to pursue your doctorate?

a. Do you think this would be different if you were enrolled full-time?

22. What services are most helpful to you as a part-time doctoral student?

23. What more could be done to support part-time doctoral students?

24. If you had to give advice to a new part-time doctoral student, what advice would you give?

25. What didn't I ask you about that is important for me to understand part-time doctoral students? 


\section{Biographies}

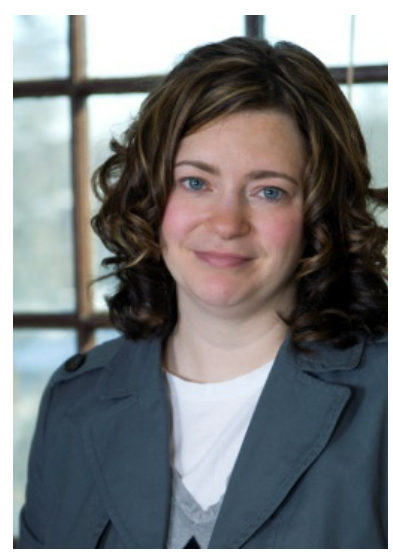

Susan K. Gardner, Ph.D. is Associate Professor of Higher Education at the University of Maine in the United States. Her research focuses on the intersections of individual and organizational development in higher education institutions, with an emphasis in social justice. She can be reached at susan.k.gardner@maine.edu.

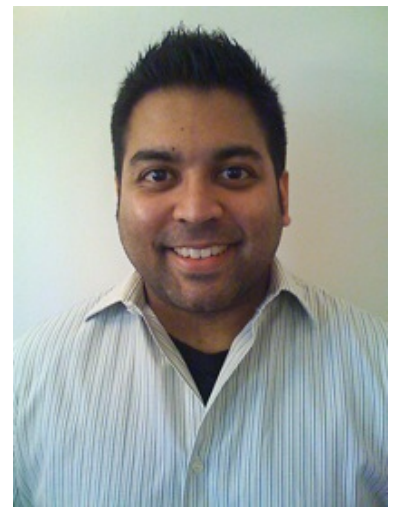

Bryan Gopaul is a doctoral candidate in the Higher Education program at OISE/UT. His doctoral research focuses on the socialization of doctoral students in Engineering and Philosophy. In addition to doctoral education, Bryan has research interests in the academic profession, critical pedagogy and the public good of higher education. For three years, Bryan worked as a TA Trainer with the Teaching Assistants' Training Program (TATP) where he provided workshops about inclusive teaching practices to TAs across the University. Finally, Bryan was a graduate student representative for the American Educational Research Association (AERA) as well as for the Graduate Education Council (GEC) of the University. 